Pre-submission draft

To be published in M.J. Versluys (ed.): Beyond Egyptomania. Objects, style and agency. Studien aus dem Warburg-Haus 21. De Gruyter.

\title{
Ancient Egypt: do things matter?
}

\author{
David Fontijn
}

When I was seven or eight years old, I visited the National Museum of Antiquities in Leiden together with my father. We passed through rooms filled with statues and vessels from the Classical world. We probably looked at displays with finds from the Near East and Dutch prehistory, but what made a tremendous impression on me - what I remember most clearly - were the rooms dedicated to Ancient Egypt. In there I saw strange, monumental, awe-inspiring statues of people with animal heads. I remember a serene statue pair of what must have been an important man and woman (the new kingdom royal treasurer Maya and his wife Merit, as I only learned much later). There was a (partial) reconstruction of the inside of a mastaba, where for a moment I could fantasise how it could be to enter the secret interior of an ancient grave. And everywhere there were these enigmatic, but iconic signs: hieroglyphs.

I cannot recall if by that time I was already sure I wanted to become an archaeologist, but this visit surely stimulated my interest in the past. Reading a draft of this book now, decades later, this memory - undoubtedly faded and transformed through time - kept coming back to me. Why did the ancient Egyptian exhibits make such an impression on me in particular? Surely not only because of the monumental size of the things displayed, as in the Classical department there were many large and impressive statues as well. Was it the fact that ancient Egyptian things were a strong 'brand' of things that are familiar and strange at the same time (as Versluys suggests in his contribution to the present volume)? Was it because of the ubiquitous pictorial hieroglyphs that were recognizable as depictions of things and animals on the one hand, but seemed so strange in representing language, on the other? Was it maybe the rigid stylistic coherence that made Egypt so different from all the other things on display? Or was it the appeal of the fact that all these things were excavated from strange structures buried underneath the desert sands? In other words: was my vision of Egypt by that time already coloured by a Romantic image of ancient Egypt (evoked by comics I had read) as a mysterious realm that was to be discovered in adventurous expeditions?

It is impossible to answer such questions today, but my first confrontation with ancient Egypt as a concept may be comparable to that of many other people - judging from how popular exhibits on ancient Egypt still are with both children and adults in the same museum today. As a matter of fact, it brings together two key themes that lie at the heart of this book: the way in which concepts of ancient 
Egypt are being produced by 'Rezeptionsgeschichte' and the role that ancient Egyptian things themselves play in creating, maintaining or altering such concepts. ${ }^{1}$ It is particularly on the latter aspect that I wish to focus here.

\section{Do ancient Egyptian things have 'agency'?}

In the editor's introduction to this book, ancient Egypt's material culture is seen as more than just representational. Versluys argues that the things themselves play a role in driving and even creating the concept of Egypt. Ancient Egyptian things are assumed to have 'agency'. With the term 'agency', a 'capacity for action' is meant. ${ }^{2}$ Although this is a straightforward and un-problematical term when used to discuss social action, ${ }^{3}$ this book enters a more controversial field by understanding agency as residing in ancient Egyptian objects themselves. It makes us pose the in fact remarkable question whether or not materials and objects - in some way - are capable of 'doing' something, of having an effect on humans that cannot be achieved through thoughts and mental considerations alone. To bring it back to my museum visit as a young boy: in what way did the objects themselves shape my vision of Ancient Egypt?

Since the early 2000s, the notion that objects - to some extent - are capable of acting has become an important theory in the Humanities. In material culture theory, it particularly came to life through the seminal book 'Art and Agency' by Alfred Gell. 'Material agency', as it came to be called, was endorsed as a game-changing theory by some but critically received by others. ${ }^{5}$ Reading this book, one equally notes some ambiguity regarding the term. Although material agency is mentioned as a key concept by Van Eck in the Preface of this book and by Versluys in his introduction, where they argue that the mnemohistory of Egypt is mediated through objects, the term is not that often used in the other contributions, even though the term agency is in the title of part II and many chapters do discuss the impact of material culture on people. There seems to be a certain uneasiness when it comes to fully

\footnotetext{
${ }^{1}$ E. Mol, 2015. Egypt in Material and Mind. The use and perception of Aegyptiaca in Roman domestic contexts of Pompeii (unpublished $\mathrm{PhD}$ thesis). Leiden: Leiden University, 2015. On 'Rezeptionsgeschichte' see the contribution of Assmann/Ebeling in this volume.

${ }^{2}$ J. Robb, Beyond Agency, in: World Archaeology 42/4 (2010), pp. 493-520, p. 493

${ }^{3} \mathrm{cf}$. A. Giddens, The Constitution of Society, Cambridge: Polity Press, 1984.

${ }^{4}$ A. Gell, Art and Agency: An Anthropological Theory, Oxford: Oxford University Press, 1998.

${ }^{5}$ e.g. Ch. Gosden, What do objects want?, in: Journal of Archaeological Method and Theory 12/3 (2005), pp. 193-211; L. Malafouris, How things shape minds. A theory of material engagement, Cambridge, MA-London: MIT Press Books, 2013; Robb 2010 (as fn. 2). But critically received by cf. contributions in D. Boschung, P.A. Kreuz, T. Kienlin (Hrsg.), Biography of Objects. Aspekte eines kulturhistorischen Konzepts, Morphomata 31, Paderborn: W. Fink Verlag, 2015; cf. Ph.W. Stockhammer, Archäologie und Materialität, in: Ph.W. Stockhammer, H.P. Hahn (Hrsg.). Lost in Things. Fragen an die Welt des Materiellen, Tübinger Archäologische Taschenbücher 12, Münster-New York: Waxmann, 2015, pp. 25-40.
} 
discussing material agency. This is perhaps understandable - after all: have not we learned since childhood that 'things' do not act? That it makes no sense to get angry at a malfunctioning computer, or to speak to a portrait of a loved one?

In this contribution, I wish to devote some more words to this topic that is prominently mentioned in the book's title, but seems to be somewhat circumvented or avoided in most contributions. How could things be considered to possess some kind of agency?

\section{Things can be like people}

If things are to possess agency, this means they are a bit like humans. Examples of things that are treated like persons can be found in every culture across the world, including our own. Although humans already learn to differ between inanimate things and animate humans in childhood, ${ }^{6}$ this does not mean that every object is treated like an inanimate thing. ${ }^{7}$ As Mauss made clear in his groundbreaking essay on the gift, there is a difference between things that can be perceived as detached or alienated from the human world they are in, and those that are inalienably linked to humans and their overarching ideas and values. ${ }^{8}$ Mauss argued that the reason why we feel obliged to reciprocate a gift, is because there is something of the giver in the thing given. Even though humans usually know all too well that objects are not people, certain objects receive the same kind of treatment that is normally reserved for people. ${ }^{9}$ For example, think of the American president hugging his national flag, or recall how painful it can be to deal with the personal belongings of a loved one after she or he has died. ${ }^{10}$ These are cases where sometimes things are apparently perceived as conveying something 'human' (personal belongings) or something related to an important collective social identity (national flag). What is interpreted as inalienably linked to the personal or social may differ from time to time and from culture to culture, but as Kopytoff reminds us: time and again, there is a certain behavioural

\footnotetext{
${ }^{6}$ I. Hodder, Entangled. An archaeology of the relationships between humans and things, Wiley-Blackwell: Oxford-Malden, MA, 2012, p. 23.

${ }^{7}$ I. Kopytoff, The cultural biography of things: commoditisation as process, in: A. Appadurai (ed.), The Social life of Things, Cambridge: Cambridge University Press, 1986, pp. 64-91.

${ }^{8}$ As M. Mauss, The gift. The form and reason for exchange in archaic societies, London: Routledge, 1993 [1923/1924]; cf. also M. Bloch, J. Parry, 1989. Introduction: money and the morality of exchange, in: J. Parry and M. Bloch (eds.), Money \& the morality of exchange, Cambridge: Cambridge University Press, 1989, pp. 131; M. Godelier, The Enigma of the Gift, Cambridge \& Oxford: Polity Press, 1999; D. Graeber, Value. Anthropological theory of Value, in: J.G. Carrier (ed.), A handbook of economic anthropology, Cheltenham/Northampton, MA: Edward Elgar Publishing Limited, 2005, pp. 439-454.

${ }^{9}$ Godelier 1999 (as fn. 8).

${ }^{10}$ See for related examples: A. Depner, Worthless things? On the difference between devaluing and sorting out things, in: H.P. Hahn and H. Weiss (eds.), Mobility, Meaning and Transformation of things: Shifting contexts of material culture through time and space, Oxford: Oxbow books, 2013, pp. 78-90.
} 
response where things are being treated as if they were humans (even though they are not). ${ }^{11}$ Statues of Saddam Hussein were systematically destroyed in public events in the aftermath of the Iraq war in $2003,{ }^{12}$ which implies they were widely regarded as personifications of the dictator himself and all that he stood for. In reality, of course, they were just sculpted stone. What is considered the 'wrong' way to treat things may 'hurt'; think for example of the destruction of ancient Assyrian heritage by ISIS - an event that almost got the same attention as the killing of tens of thousands of people in the same war. There also may be certain, (implicit) social expectations and evaluations as to how to deal with things. In museums all over the world, objects from Ancient Egypt are usually displayed in their own rooms or wing, often subdivided thematically, parallel to rooms showing objects from other ancient 'civilizations' ${ }^{13}$ In western museums, they are usually not part of one single exhibition displaying the long-term history of Egypt itself, which would include Coptic and Islamic objects. This reifies the notion that ancient Egypt, in the mind of westerners, lacks a connection to what came later, although all are part of the history of that part of Africa that is now the modern Egyptian state. ${ }^{14}$

Thus, things can be like people. This becomes clear and researchable from the behavioural response that things may arouse. As Kopytoff sets out in his seminal paper, every culture has specific (but usually implicit) expectations on what is considered the proper treatment of things. ${ }^{15}$ Ancient Egyptian people from the late 18th dynasty must have had clear ideas about what would be the 'right' way to deal with the statues of treasurer Maya and his wife Merit, just like we have today. It would probably be considered inappropriate if the statues were placed in an amusement park, or if we would allow people to sit on Maya's lap to make selfies.

\section{Do objects and materials shape thinking?}

The 'agency' of things is often supposed to involve more than simply the process whereby certain things incite certain behaviour. From a phenomenological point of view, an argument from cognitive science would be that things 'do' much more than that - they may be integral to thinking itself. Using theories from cognitive science and neuropsychology, Malafouris (2013) recently argued that the brain works in such a way that the material environment shapes people's thinking. ${ }^{16} \mathrm{He}$ argues that people use things to think with. Referring to Bateson's famous example of the blind man and the stick he uses

\footnotetext{
${ }^{11}$ Kopytoff 1986 (as fn. 7).

${ }^{12}$ F. Göttke, Toppled, Rotterdam: Post Editions, 2010.

${ }^{13}$ See the contribution of Hurley in this volume.

${ }^{14} \mathrm{See}$ also the contribution of Quirke in this volume.

${ }^{15}$ Kopytoff 1986 (as fn. 7).

${ }^{16}$ Malafouris 2013 (as fn. 5).
} 
to orientate himself in the invisible world, the point can be made that the stick is just as much part of the blind's man thinking as his brain is ${ }^{17}$ Alternatively, following Renfrew we may ask ourselves whether certain concepts are conceivable without things or bodily experiences. ${ }^{18}$ For example, Renfrew asks himself whether the concept of weight is conceivable without having had the experience of weighing, or whether we can have an idea of 'value' without ever having dealt with valuables. ${ }^{19}$ In our case, the following question matters: is 'ancient Egypt' conceivable for someone who has never seen 'ancient Egyptian things'? This is a question that is less often asked, ${ }^{20}$ but one that lurks in the background of this book and is hinted at by Versluys in his introduction.

Malafouris argues that things have mediational effects; that is, they affect and transform the relation between people and their environment. ${ }^{21}$ Others have argued that things may work to anchor or materialize time. ${ }^{22}$ Monuments like pyramids were built during one specific moment in time, but by means of their visuality and material presence have become enduring elements of the visual world they are just as much part of modern Egypt as they were of Egypt during the Old Kingdom. By occupying space they 'slow down time' ${ }^{23}$ Because of the way ancient Egyptian things are being thematically ordered in modern museums, reifying a superficial stylistic unity, it is easy to forget that sometimes thousands of years separate the production of one item from another. Following Kirsh, Malafouris makes the point that the organization of space itself shapes thinking: "by supporting choice, by supporting perception, and by supporting problem solving" (italics as in the original). ${ }^{24}$ This brings to mind how a particular way of displaying ancient Egyptian things in museums or popular culture, may have the effect to create a particular notion of ancient Egypt. ${ }^{25}$ One could think of classic displays where ancient Egypt is represented as one monolithic whole, separate from adjacent or younger cultures, suppressing stylistic deviances, emphasizing orthodox monuments over popular material culture, etc.

\footnotetext{
${ }^{17}$ See G. Bateson, Steps to an Ecology of Mind. Chicago: University of Chicago Press, 1973, as quoted in Malafouris 2013 (as fn. 5), p. 4-7.

${ }^{18} \mathrm{C}$. Renfrew, Commodification and Institution in Group-Oriented and Individualizing Societies, in: W.G. Runciman (ed.), The Origin of Human Social Institutions, Proceedings of the British Academy, Oxford: Oxford University Press, 2001, pp. 93- 117, p 95, pp. 97-99.

${ }^{19}$ Renfrew 2001 (as fn. 18), p. 99; cf. also D.R. Fontijn, Economies of Destruction. How the systematic destruction of valuables created value in Bronze Age Europe, c. 2300-500 BC, London-New York: Routledge, 2019.

${ }^{20}$ See Mol 2015 (as fn. 1) for an exception.

${ }^{21}$ Malafouris 2013 (as fn. 5), pp. 245-6.

${ }^{22} \mathrm{cf}$. B. Olsen, In Defense of Things. Archaeology and the Ontology of Objects, Lanham: AltaMira Press, 2010.

${ }^{23}$ Malafouris 2013 (as fn. 5), p. 247; but see for a different view I. Hodder, Wheels of Time. Some aspects of entanglement theory and the secondary product revolution, in: Journal of World Prehistory 24 (2011), pp. 175187, p. 179.

${ }^{24}$ Following Kirsh (1995), Malafouris 2013 (as fn. 5), p. 72.

$25 \mathrm{cf}$. the contributions by Nouvel-Kammerer and Hurley in this volume.
} 
4. "To see is to be"

This quote, taken from Buchli, ${ }^{26}$ was originally used to describe the significance of seeing and experiencing distant holy places for the constitution of personhood of pilgrims from the fifth century AD. It also matches the point made above and underscores that seeing and experiencing the material itself constitutes more than humans receiving sensory impulses; as some scholars have put it, ${ }^{27}$ it is rather that seeing/experiencing ontologically is a constitutive act: "minds and things are co-constituted in situated action" 28 .

In spite of all the changes Egypt went through, it can be said that anchoring concepts, notions, and ideas on the overarching supernatural realm in concrete things was a long-term concern of ancient Egyptian cultures ${ }^{29}$. Making ideas on the divine, kingdom, or social order 'manifest' in the material seems to have been essential ${ }^{30}$. Why this was such a long-lived strategy is an intriguing question but difficult to answer- did it help to naturalize apparent contradictions and inconsistencies in the pantheon or creation myths when different sun-related gods were made real to people by being shown in depictions or statues that were visible to all? Was the notion of a human king as a divine being dwelling on earth better conceivable to the people once his larger-than-life portrayal on par with gods was ubiquitous? $?^{31}$

This is relevant because conveying information through permanent and lasting materiality and visuality is just one particular way of information management. Creating memories by making things in-visible is another. ${ }^{32}$ In many cultures all over the world, the deliberate removal of material culture from society can - paradoxically - also have the effect that the thing that is removed or even destroyed attains a certain inalienability and endurance in the mind of onlookers just because of the fact it is now

\footnotetext{
${ }^{26}$ V. Buchli, An Archaeology of the Immaterial, London/New York: Routledge, 2016, p.47.

${ }^{27}$ Mol 2015 (as fn. 1), p. 82-87; Malafouris 2013 (as fn. 5), p. 77.

${ }^{28}$ Malafouris 2013 (as fn. 5), p. 77.

29 On 'anchoring': Hutchins, E. 2005. Material anchors for conceptual blends, Journal of Pragmatics 37, 15551577.

30 Hutchins 2005, see fn 29.

${ }^{31} \mathrm{cf}$. Amenophis III/Akhenaten; N. Reeves, Akhenaten. Egypt's False Prophet, London: Thames \& Hudson, 2001; cf. also on the significance of visual styles in the construction of identity and power relations M.J. Versluys, Visual Style and Constructing Identity in the Hellenistic World. Nemrud Dăg and Commagene under Antiochos I, Cambridge: Cambridge University Press, 2017.

${ }^{32}$ D.R. Fontijn, The significance of 'invisible’ places, in: World Archaeology 39/1 (2007), pp. 70-83; Fontijn 2019 (as fn. 19); M.J. Rowlands, The role of memory in the transmission of culture, in: World Archaeology 25 (1993), pp. 141-151.
} 
gone. ${ }^{33}$ Intriguingly, strategies aiming at visibility and those achieving invisibility often go together. ${ }^{34}$ This is even true for such an outspoken monumentalizing and visual culture as that of ancient Egypt. It was only long after my first visit to the Egyptian exhibition at the Leiden museum, that I came to realize that many things on display were objects specifically made for funerals - it was never the ancient Egyptians' intention that they would come to light again. This is true for many other star objects of archaeological and anthropological museums worldwide, like the massively destroyed metalwork of the European Bronze Age, or the elaborate Malanggan wood sculptures of New Ireland. ${ }^{35}$ This brings me to another reason why Egypt may have played such a prominent role in western discourses: the fact that the ancient Egyptians not only produced so many splendid objects, but that they dedicated so much of that 'wealth' to the supernatural and divine world, by storing it permanently underground, in seemingly inaccessible tombs. Narratives of ancient Egyptian people hiding special things from the living for the afterlife, and the possibility that one day, modern people may retrieve those things again are among the most appealing features of ancient Egypt since the Napoleonic expeditions.

\section{Agency of things and histories of ideas}

Following the editor's introduction, its intriguing questions keep lurking in the background. How is it possible that the legacy of ancient Egypt acquired such a central role in later cultures, starting with the ancient Greeks and Romans? Was this because ancient Egyptian material culture has a unique agency? Was it because of unique contingencies in the meta-narratives on ancient Egypt in younger civilizations?

Cognitive science and neuropsychology have brought us new insights on how materiality and visuality are inextricably linked with how human thought is shaped. ${ }^{36}$ This implies that the question whether or not a concept of ancient Egypt can exist without ancient Egyptian things is in fact no longer an interesting one - seeing that, in fact, they constitute each other. ${ }^{37}$ When reviewing the contributions in this book and other works on "Egyptomania", it indeed becomes clear that the revival of notions

\footnotetext{
${ }^{33}$ Fontijn 2019 (as fn. 19); Rowlands 1993 (as fn. 30); D. Wengrow, 'Archival' and 'Sacrificial' Economies in Bronze Age Eurasia. An interactionist Approach to the hoarding of metal, in: T.C. Wilkinson, S. Sherratt and J. Bennet(eds.), Interweaving Worlds. Systemic Interactions in Eurasia, $7^{\text {th }}$ to the $1^{\text {st }}$ Millennia BC, Oxford: Oxbow Books, 2011, pp. 135-144.

${ }^{34}$ Fontijn 2019 (as fn. 19).

${ }^{35}$ S. Küchler, Sacrificial economy and its objects, in: Journal of Material Culture 2 (1997), pp. 39-60.

${ }^{36} \mathrm{cf}$. the overview in Malafouris 2013 (as fn. 5).

${ }^{37}$ cf. Malafouris 2013 (as fn. 5), p. 77.
} 
surrounding ancient Egypt often co-occurs with moments when other people became physically confronted with its material legacy in one way or other (e.g. the inclusion of Egypt as part of the Roman Empire, Napoleon's expeditions into Egypt, or for that matter: the discovery of Tutankhamen's tomb). It also becomes clear that the way in which ancient Egyptian things were displayed, used and portrayed in later periods mattered greatly to the impact and significance they had. $^{38}$

This book also convincingly shows how the mnemohistory centred around ancient Egypt has come to be firmly anchored in discourse on western self-identity (and self-congratulation). It is remarkable that this seems less the case for other ancient civilizations, from adjacent West Asia, other parts of Africa or even from Europe itself, even though these have also created an impressive, enduring material legacy (think for example of the monumental remains from the ancient city of Babylon, the Benin civilization or the megalithic landscape of Stonehenge). At least, we can say that the role of the West Asian, African and European pasts differ from the role played by ancient Egypt in the preferred 'grand narrative' on western identity. It is here that the questions concerning the agency of ancient Egyptian things again become relevant. Did ancient Egypt's material culture have such an impressive afterlife because it had an "immediacy" or "unmittelbare Sagkraft" 39 that others lacked, for example because of its unparalleled stylistic coherence throughout time? Modern computational techniques (e.g. 3Dscanning and visual recognition software) now make it possible to verify such statements to some extent, but they risk to locate the nature of ancient Egyptian material culture in essentialist (visual) features. What people did with these things, how their materiality and visuality was managed in situated social practice is perhaps even more important. ${ }^{40}$ It is in this field that I see the greatest potential for archaeology and other material culture studies, such as museum studies: how were ancient Egyptian things treated, used and located in space? $?^{41}$

It may be extremely difficult to get into the head of people. However, what people were doing is researchable from archaeological and historical evidence, to some extent - patterned behavioural responses to things. ${ }^{42}$ This is particularly useful when it comes to investigating the attitude towards Egyptian things in non-Egyptian cultures, such as the Hittites, or the later Greeks and Romans. From among the array of long-distance links they entertained, which imported things did these people include in their lives and what role did things from Egypt play? Which Egyptian things were included

\footnotetext{
${ }^{38}$ As illustrated in the contributions by Günther, Swetnam-Burland, Nouvel-Kammerer and Hurley in this volume.

${ }^{39}$ As Assmann and Ebeling in this volume quoting H.G. Gadamer, Wahrheit und Methode, Tübingen: Mohr, 1990, pp. 295.

${ }^{40}$ Sensu Giddens 1984 (as fn. 3).

${ }^{41}$ As for example done by Mol 2015 for Egyptian and Egyptianizing things in Roman context (as fn. 1).

42 'Average behaviour', cf. Ph. Ball, Critical Mass. How one thing leads to another, London: Arrow Books, 2005.
} 
(and which were not), in which contexts, in which practices? Did Egyptian styles influence existing 'style communities'?

Much ink has been spilt on why it is wrong to use human terms when describing what happened to things. ${ }^{44}$ This reduces the discussion on how things shape human thinking to a semantic one, which is not very productive for empirical research. It is essential to the human condition that, on the one hand, we recognize ourselves as different from things, but that we at the same time may connect to the world around us by seeing things $a s$ if they were alive.

\section{Acknowledgments}

I wish to thank the editor to invite me to write this. I am thankful for his comments as well as those from an anonymous reviewer on a previous draft of this text. Many thanks are also to dr Eva Mol (Brown University), dr Marike van Aerde and Suzan van de Velde (Leiden University) for comments and practical help.

\footnotetext{
${ }^{43} \mathrm{cf}$. M.H. Feldman, Communities of Style. Portable Luxury Arts, Identity, and Collective Memory in the Iron Age Levant, Chicago and London: University of Chicago Press, 2014.

${ }^{44}$ Such as the critique on the idea that things may be considered to have had a biography; cf. contributions in Boschung et al. 2015 (as fn. 5); for a critique against treating humans and things on equal terms: Hodder 2011 (as fn. 23), p. 179)
} 